\title{
Quantification of Interplaying Relationships Between Wellbeing Priorities of Aboriginal Peoples in Remote Australia
}

Rosalie Schultz

Flinders University, rosalie.schultz@flinders.edu.au

Stephen J. Quinn

Swinburne University of Technology, Melbourne

Tammy Abbott

Ninti One, Alice Springs

Sheree Cairney

Flinders University \& CRC-REP

Jessica Yamaguchi

Department of Prime Minister and Cabinet, Australian Government, Canberra 


\title{
Quantification of Interplaying Relationships Between Wellbeing Priorities of Aboriginal Peoples in Remote Australia
}

\begin{abstract}
Wellbeing is a useful indicator of social progress because its subjectivity accounts for diverse aspirations. The Interplay Research Project developed a wellbeing framework for Aboriginal Peoples in remote Australia comprising government and community wellbeing priorities. This article describes statistical modelling of community priorities based on surveys administered by community researchers to 841 participants from four remote settlements. Constructs for Aboriginal language literacy, cultural practice, and empowerment were identified through exploratory factor analysis (EFA); structural equation modelling (SEM) was used to confirm relationships. Cultural practice was associated with Aboriginal language literacy and empowerment, which were both associated with wellbeing. Aboriginal literacy and empowerment mediated negative direct relationships between cultural practice and wellbeing. Direct relationships were significant only for females for whom empowerment and Aboriginal literacy appear key to enhancing wellbeing.
\end{abstract}

\section{Keywords}

culture, empowerment, gender, Indigenous languages, Indigenous literacy, wellbeing

\section{Acknowledgments}

The Interplay Research Project was supported by funding from the Australian Government Cooperative Research Centre Program through the Cooperative Research Centre for Remote Economic Participation (CRC-REP, hosted by Ninti One Limited). We acknowledge the support and involvement of our key organisational stakeholders: Department of Prime Minister and Cabinet, Australian Bureau of Statistics, Centre for Remote Health (Flinders University and Charles Darwin University), Flinders NT-Katherine, Poche Centre for Indigenous Health and Wellbeing Northern Territory, Banatjarl Strongbala Wumin Grup, Central Desert Native Title Services, Dhimurru Aboriginal Corporation, Kalano Community Association, Katherine Stolen Generations Group, Layhnapuy Homelands Aboriginal Corporation, Marthakal Homelands Resource Centre, Martu Rangers (Wiluna), Miwatj Health Aboriginal Corporation, Muntjiltjarra Wurrgumu Group, Northern Star Resources, Ngangganawili Aboriginal Health Service Community, StrongBala Men's Health Program, Wurli-Wurlinjang Health Service, Yalu Marngithinyaraw Aboriginal Corporation, and Yolngu Business Enterprises. Rosalie Schultz received support from a scholarship from Vincent Fairfax Family Foundation through the Royal Australasian College of Physicians. Jessica Yamaguchi is an Advisor working for the Australian Government.

\section{Disclaimer}

The views and opinions expressed in this article are those of the authors and do not reflect the views of the Department of the Prime Minister and Cabinet, the Australian Government, or any State or Territory Governments.

\section{Creative Commons License (c) (1) (9)}

This work is licensed under a Creative Commons Attribution-Noncommercial-No Derivative Works 4.0 License. 


\section{Quantification of Interplaying Relationships Between Wellbeing Priorities of Aboriginal People in Remote Australia}

Wellbeing is the experience of flourishing and feeling satisfied with life (Adler \& Seligman, 2016). Wellbeing is an individual, subjective experience, making it a useful indicator to compare social progress across different cultures and time periods between people and populations who may have different values and goals (OECD, 2017).

Subjective aspects of wellbeing include experiences and perceptions, and these can be measured only by specifically inquiring, for example about life satisfaction (OECD, 2017). Socio-economic indicators are considered objective aspects of wellbeing, since they do not require people to assess themselves (OECD, 2017). However, decisions about which socio-economic indicators to measure and how to measure them reflect culturally influenced values and goals; this means that even if measurement is objective, the indicators themselves reflect subjective assessment about what is important (Tov \& Au, 2013). Thus, even notionally objective indicators of wellbeing can reflect cultural bias and negative attitudes towards Aboriginal and other minority people (Cairney et al., 2017).

Aboriginal Australians ${ }^{1}$ have occupied Australia for over 50,000 years. They identify themselves as distinct from other Australians and maintain their diverse cultures, languages, and histories (Australian Institute of Health and Welfare, 2015). Many Aboriginal people maintain strong connections to their country: their "land, sea, sky, rivers, sites, seasons, plants and animals; place of heritage, belonging and spirituality," and they hold Aboriginal knowledge (Australian Museum, 2017). Aboriginal people are less urbanised than other Australians, with $21 \%$ living in the remote regions which make up $85 \%$ of Australia's land area, compared with only $1.7 \%$ of all Australians (Australian Institute of Health and Welfare, 2014; Walker, Porter, \& Marsh, 2012). Aboriginal people in remote regions of Australia may be on their traditional or ancestral lands (Altman, 2007). Many hold significant land assets or rights; yet, 53\% experience income poverty (Markham \& Biddle, 2018). Compared with other Australians, Aboriginal people are considered disadvantaged based on a wide range of indicators, including education, employment, health, housing, income, and criminal justice, with most indicators for Aboriginal people in remote regions suggesting greater disadvantage compared with urban Aboriginal people (Australian Institute of Health and Welfare, 2015; Commonwealth of Australia: Department of Prime Minister and Cabinet, 2018).

Despite these statistics, Aboriginal people in remote regions report high levels of wellbeing, with their mean general life satisfaction at 7.6 on a scale from 0 to 10 . This is equivalent to the mean life satisfaction of all Australians, while Aboriginal people outside of remote regions report lower levels of life satisfaction, with a mean of 7.2 (Australian Bureau of Statistics, 2015, 2016).

Aboriginal people in remote regions often have stronger connections to country and more opportunities to participate in cultural practices than people in non-remote regions, and these factors may contribute to their higher levels of wellbeing (Davies et al., 2010). Cultural practices such as art and craft, ceremony, caring for country, and hunting and gathering contribute to the wellbeing of Aboriginal

\footnotetext{
${ }^{1}$ Indigenous Australians include both Aboriginal and Torres Strait Islander Peoples. This research involved Aboriginal communities, where people collectively prefer to be identified as Aboriginal, so the term Aboriginal is used throughout, except where Torres Strait Islander people are included and in international contexts where we refer to Indigenous Peoples.
} 
people throughout Australia including in urban regions (Burgess et al., 2009; Hill et al., 2013; Hunt, 2012). Analysis of the National Aboriginal and Torres Strait Island Social Survey (NATSISS) conducted in 2008 showed that having a cultural identity, speaking Aboriginal languages, and participating in traditional economic activities contribute to people's wellbeing, particularly in remote regions (Dockery, 2012). An economic analysis commissioned for Australia's national government quantified social return on investment in cultural practice for Aboriginal Peoples in remote communities at 29\% per year. This analysis identified specific benefits that Aboriginal Peoples gain from participation in cultural activities, including strengthening their skills, confidence, and health, but these were not quantified (Social Ventures Australia, 2016). A case study from the Northern Territory identified health, economic, and social wellbeing benefits of cultural practice for participants in Aboriginal cultural and natural resource management, and recommended quantification of these relationships (Barber, 2015).

Cultural practices contribute to wellbeing and also to empowerment, which is defined as individuals and groups gaining control over their lives, encompassing both personal development and structural change (Wallerstein, 2006). Empowerment reflects cultural, social, and environmental contexts; for Indigenous Australians, spirituality and personal values and strengths are particularly linked to empowerment (Whiteside, Tsey, \& Earles, 2010). Empowerment has potential to address broad socio-economic inequalities, such as those borne by Aboriginal Australians, because it enables individuals and communities to participate in and drive structural change (Haswell et al., 2010). The process of empowerment is of particular importance for Aboriginal Peoples because it depends on cultural context and contributes to wellbeing (Pease, 2002; Wallerstein, 2006).

Australian Aboriginal languages are also linked to wellbeing and empowerment and are important as sources of culture, identity, and knowledge (Marmion, Obata, \& Troy, 2014). Analysis of the NATSISS illustrated how Aboriginal languages enable people to communicate cultures and worldviews, providing a connection between culture and wellbeing (Biddle \& Swee, 2012).

NATSISS showed that Australian Aboriginal men and women report different cultural strengths. Speaking and understanding Aboriginal languages varies by age and gender. More men participate in harvesting cultural practices, and more older men speak and understand Aboriginal languages, while more women participate in cultural production, including arts and crafts, music, dance, theatre and storytelling. Each of these aspects of culture contributes to societal sustainability and wellbeing, and they are stronger for Aboriginal Peoples in remote regions compared to urban areas (Biddle \& Swee, 2012).

Wellbeing for Aboriginal Peoples in remote regions of Australia was the focus of the Interplay Research Project, undertaken through the Cooperative Research Centre for Remote Economic Participation (CRC-REP) as part of its broad-reaching investigation into economic development and participation of people in remote Australia (Cooperative Research Centre for Remote Economic Participation, 2017). Government departments responsible for funding programs for Indigenous Australians, researchers employed by the CRC-REP, and community members collaborated in development of the research (Cairney \& Abbott, 2014).The project name Interplay was chosen to draw attention to the interplaying relationships between different wellbeing priorities. This article aims to quantify relationships between cultural practice and wellbeing, including through mediating variables (Nitzl, Roldan, \& Cepeda, 2016). We hypothesised that cultural practice, literacy in Aboriginal languages, and empowerment each contribute to wellbeing for Aboriginal Peoples in remote communities. Alternatively, there may be 
mediation between variables in their relationships to wellbeing (Cairney et al., 2017). Understanding relationships between wellbeing priorities can enable services to better address the wellbeing needs of Aboriginal Peoples in remote regions.

\section{Methods}

The Interplay Research Project was conceived and governed through the CRC-REP, as part of its exploration of issues surrounding economic participation in remote Australia, particularly for Aboriginal and Torres Strait Islander Peoples (Cooperative Research Centre for Remote Economic Participation, 2017). Aboriginal People led governance and management of the project (Cooperative Research Centre for Remote Economic Participation, 2017). Researchers and government agencies responsible for services in remote regions worked closely with Aboriginal community members in the research development. Through a conceptual shared space of knowledge exchange and learning, we aimed to ensure the project met research needs of both government and communities (Cairney \& Abbott, 2014). The shared space is shown diagrammatically in Figure 1 (Nguyen \& Cairney, 2013).

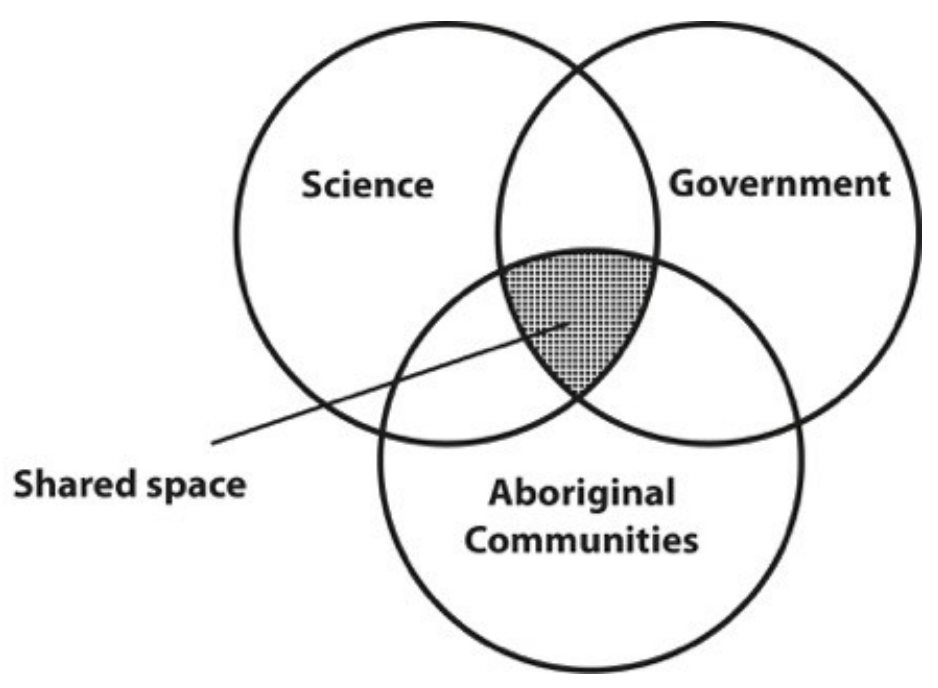

Figure 1. Shared space approach represented diagrammatically where areas of knowledge of each research partner group are brought together to overlap. 


\section{Ethical Considerations}

The Interplay Research Project prioritised engagement and collaboration with Aboriginal community organisations, land councils, and local partner organisations to ensure the project fit with the research interests of Aboriginal Peoples, particularly participants in the research. This approach aimed to ensure a fundamentally decolonised and ethical approach to the research (Smith, 2012). The Northern Territory Department of Health/Menzies School of Health Research Ethics Committee (Reference 2013-2125) and the Western Australian Aboriginal Health Ethics Committee formally approved the research (Reference 549). All survey participants gave written consent, in addition to the guardians of participants under 16 years. On-going working relationships, including further research projects, contribute to the integrity of the approach, providing cultural feedback and evaluation to non-Aboriginal researchers (Cairney \& Abbott, 2014).

\section{Research Population}

Members of Aboriginal communities throughout remote regions of Australia were the population of interest in the Interplay research. Communities were invited through the CRC-REP to indicate their capacity and interest to be involved, and four communities were selected to ensure inclusion of different geographies, levels of remoteness, population sizes and proportions of Aboriginal people, and extent of use of Aboriginal languages. Geography, demography, and participation in the research by each community are shown in Table 1.

\section{Development of the Interplay Wellbeing Framework and Survey}

Aboriginal Peoples from the communities in the study collaborated with researchers to develop the Interplay Wellbeing Framework, which emerged through a series of workshops (Cairney, Abbott, \& Yamaguchi, 2015). Communities' major priorities for wellbeing, namely community itself, culture, and empowerment, and government priorities of education, employment, and health comprised the basis of the wellbeing framework as shown in Figure 2.

To explore interrelationships between wellbeing priorities, the Interplay Wellbeing Survey was developed. Initially, we conducted a comprehensive search for assessment tools that were statistically and culturally validated to measure aspects of wellbeing for Aboriginal Australians (Cairney et al., 2015). While these tools were broadly suitable, there was concern by Aboriginal community researchers about their appropriateness for people in remote communities. All the tools were in English, while many Aboriginal Peoples in remote regions do not speak English well or at all (Biddle, 2012). Language issues were compounded by concepts in the assessments that were considered difficult to translate or understand. Aboriginal community members and researchers worked with other researchers familiar with the tools to carefully review and refine the words of each question, to ensure a shared understanding of meaning and comprehension across different language groups. Working together to refine the survey questions also contributed to shared ownership of and commitment to the final Interplay Wellbeing Survey. This enabled the Aboriginal community researchers to administer the Interplay survey in their home communities to people from different language groups and levels of English proficiency (Cairney et al., 2015). 
Table 1. Community Geography, Remoteness, Demography, Language, and Research Participation

\begin{tabular}{|c|c|c|c|c|}
\hline Community & 1 & 2 & 3 & 4 \\
\hline Geography & River & Island & Desert & Coastal \\
\hline $\begin{array}{l}\text { Distance from major } \\
\text { population centre }\end{array}$ & $300 \mathrm{~km}$ & $500 \mathrm{~km}$ & $1000 \mathrm{~km}$ & $650 \mathrm{~km}$ \\
\hline Remoteness classification & Remote & Very remote & Very remote & Very remote \\
\hline Total population & 9,207 & 2,550 & 1,158 & 843 \\
\hline Proportion Aboriginal & $24.2 \%$ & $88.6 \%$ & $24.4 \%$ & $75.3 \%$ \\
\hline $\begin{array}{l}\text { Primary community } \\
\text { language }\end{array}$ & Kriol & Djambarrpuyngu & Martu & Gumatj \\
\hline $\begin{array}{l}\text { Proportion of Aboriginal } \\
\text { Peoples who use Aboriginal } \\
\text { languages at home }\end{array}$ & $25.7 \%$ & $98.1 \%$ & $63.5 \%$ & $84.3 \%$ \\
\hline $\begin{array}{l}\text { Participants in Interplay } \\
\text { research }\end{array}$ & 545 & 104 & 51 & 141 \\
\hline $\begin{array}{l}\text { Proportion of } 15 \text { to } 34 \text {-year } \\
\text { age group who participated }\end{array}$ & $78.8 \%$ & $13.6 \%$ & $46.6 \%$ & $49.1 \%$ \\
\hline
\end{tabular}

Note. Population data (Australian Bureau of Statistics, 2011).

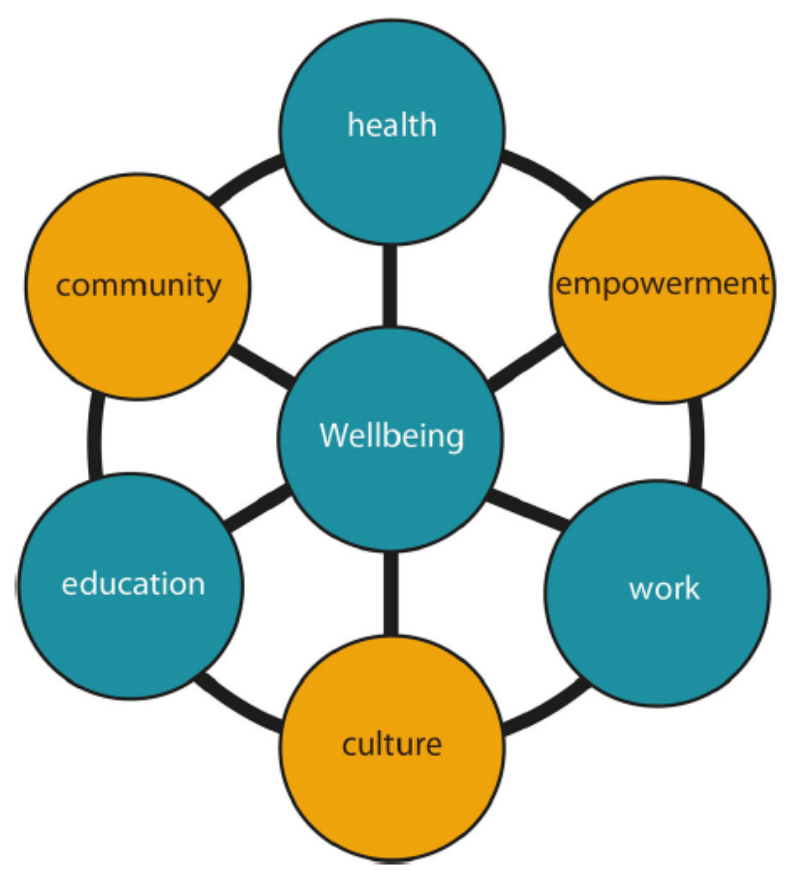

Figure 2. Interplay Wellbeing Framework comprising community priorities in amber and government priorities in turquoise. 


\section{Data Collection}

Aboriginal community researchers administered the survey from iPads in their home communities between June 2014 and July 2015 (Cairney et al., 2017). Since the research arose from the CRC-REP, people aged 15 to 34 were selected because it is typically within this age range that people transition from education to employment. We aimed to include 800 to 1,000 participants to provide a sample large enough for structural equation modelling and to achieve broad representation of the Aboriginal Peoples in the communities involved in the study (Cairney et al., 2015; Wolf, Harrington, Clark, \& Miller, 2013).

\section{Statistical Methods}

Data analysis was conducted using the statistics packages SPSS and AMOS Version 25 (Arbuckle, 2017; SPSS Inc, 2015). Missing data were calculated using multiple imputations, using the median as the most likely value. To reinforce the strength-based approach, items were recoded so that higher response values represented more positive impacts and greater wellbeing.

Exploratory factor analysis (EFA) was performed using maximum likelihood extraction with promax rotation. Factors were selected with eigenvalues greater than one, strong loadings $(>0.4)$, discriminant and face validity, adequate reliability based on Cronbach's alpha $>0.70$, and no cross-loading between survey questions (Williams, Brown, \& Onsman, 2010). Constructs were identified for Aboriginal language literacy, cultural practice, and empowerment. Table 2 shows the survey items and Table 3 descriptive statistics for each construct, while Table 4 shows Pearson bivariate correlations between the constructs.

Based on hypothesized relationships between Aboriginal language literacy, cultural practice, and empowerment a structural equation model of wellbeing was constructed (Arbuckle, 2017; Kline, 2016). The model was validated through absolute and incremental fit indices, namely chi-square, RMSEA, SRMR, CFI, TLI, and PNFI (Hooper, Coughlan, \& Mullen, 2008). Cook's distance was employed to examine for the presence of influential observations, and variance inflation factors for multicollinearity (Kline, 2016).

The positive association between cultural practice and wellbeing anticipated from the literature and research development were not confirmed in the statistical models, suggesting a more complex interplay of factors (Cairney et al., 2017). To explore this association, mediation analysis of the relationship by Aboriginal language literacy and empowerment was conducted. Bootstrapping was required in the mediation analysis to determine $95 \%$ confidence intervals and statistical significance of direct and indirect relationships (Nitzl et al., 2016). From these models, relationships of wellbeing with cultural practice, Aboriginal language literacy, and empowerment were calculated.

Gender and age were considered as possible confounding factors and multigroup analysis was performed. Participants were grouped by gender and age group: under 20, 20 to 24, and over 24. Age 20 was selected to separate the younger age categories because it often marks the division between education and employment, and 24 years was selected as the dividing line between the older age categories because it is the median age of the research participants. 
Table 2. Constructs Derived from Exploratory Factor Analysis of Survey Items

\begin{tabular}{lcc}
\hline \multicolumn{1}{c}{ Construct } & Survey items contributing & Score \\
\hline Aboriginal language literacy & Reading & 0 to 4 \\
Writing & \\
Cultural practice & Caring for country & 0 to 4 \\
Hunting and gathering & \\
Empowerment & Self-efficacy & 0 to 4 \\
& Identity & \\
Wellbeing & Resilience & 1 to 10
\end{tabular}

Table 3. Descriptive Statistics of Constructs and Wellbeing

\begin{tabular}{lcccccc}
\hline \multicolumn{1}{c}{ Construct } & Range & Mean & $\begin{array}{l}\text { Standard } \\
\text { deviation }\end{array}$ & Skewness & Kurtosis & $\begin{array}{c}\text { Cronbach's } \\
\text { alpha }\end{array}$ \\
\hline $\begin{array}{l}\text { Aboriginal } \\
\text { language } \\
\text { literacy }\end{array}$ & $0-4$ & 2.33 & 1.61 & -0.31 & -1.49 & 0.96 \\
$\begin{array}{l}\text { Cultural } \\
\text { practice }\end{array}$ & $0-4$ & 2.99 & 1.27 & -1.11 & 0.081 & 0.82 \\
$\begin{array}{l}\text { Empowerment } \\
\text { Wellbeing }\end{array}$ & $0-4$ & 3.34 & 0.82 & -1.22 & 0.98 & 0.84 \\
& $1-10$ & 8.07 & 1.94 & -0.65 & -0.63 & \\
\hline Note. $N=841$. All calculations used the SPSS statistics package (SPSS Inc., 2015).
\end{tabular}




\section{Results}

\section{Descriptive Data}

From the four communities in the research, 841 Aboriginal Peoples completed the survey, $45 \%$ of the target age range 15 to 34 years, with community coverage ranging from $13.6 \%$ to $78.8 \%$, as shown in Table 1. Mean age of participants was 25.2 years, with standard deviation 5.3 years, while median age was 24 years. All participants identified as either male $(n=352,42 \%)$ or female $(n=489,58 \%)$.

Participants reported high levels of wellbeing with mean score 8.07 out of 10 . Males and females reported similar scores $\left(\chi^{2}=13.0, d f=9, p=0.16\right)$, while younger people reported higher wellbeing (under 20: $M=8.3 ; 20$ to 24 years: $M=8.2$; over 24 years: $M=7.9 ; \chi^{2}=31.3, d f=18, p=0.027$ ).

Exploratory factor analysis identified three constructs, shown in Table 2. Aboriginal language literacy is comprised of how well people reported they could read and write in their main Aboriginal language; cultural practice is comprised of participation in caring for country and hunting and gathering; and empowerment is comprised of resilience, self-efficacy, and identity. All constructs showed a negative skew. Table 3 shows means, standard deviations, and Cronbach's alpha (a measure of reliability) for each construct.

\section{Bivariate Relationships}

Aboriginal language literacy, cultural practice, and empowerment were all statistically correlated with one another, while Aboriginal language literacy and empowerment were correlated with wellbeing. There was no statistical relationship between cultural practice and wellbeing, as shown in Table 4.

\section{Structural Equation Modelling}

Based on hypotheses of associations between cultural practice, Aboriginal language literacy, empowerment, and wellbeing, structural equation modelling was used to quantify these relationships and develop the model in Figure 3. All relationships were statistically significant, and the model showed good fit statistics $\left(\chi^{2}=49.4, d f=15 ; \chi^{2} / d f=3.29\right.$; RMSEA = 0.052 $(0.037,0.069)$; RMR = 0.036; CFI = 0.99; PNFI = 0.53; Hooper et al., 2008). Cook's distance maximum was 0.058 indicating that there were no influential outliers, while variance inflation factors showed multicollinearity was not statistically present $(\mathrm{VIF}<10)$. 
Table 4. Pearson Bivariate Correlations for Constructs of Aboriginal Literacy, Cultural Practice, and Empowerment

\begin{tabular}{lccc} 
& $\begin{array}{c}\text { Aboriginal language } \\
\text { literacy }\end{array}$ & Cultural practice & Empowerment \\
\hline Cultural practice & $0.29^{* * *}$ & & \\
Empowerment & $0.19^{* * *}$ & $0.20^{* * *}$ & \\
Wellbeing & $0.23^{* * *}$ & $0.003 \mathrm{NS}$ & $0.14^{* * *}$ \\
\hline
\end{tabular}

Note. ${ }^{* * *} p<0.001 . \mathrm{NS}=$ not significant.

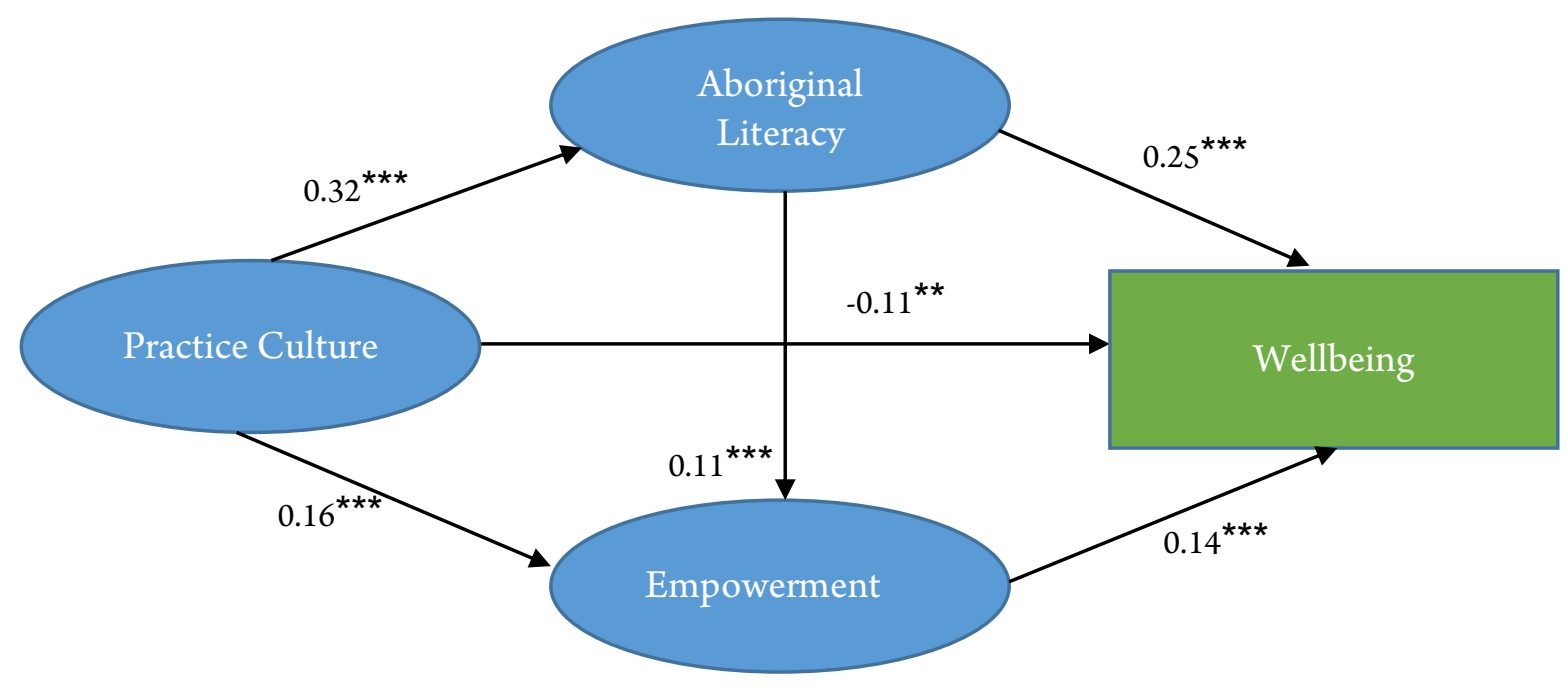

Figure 3. Structural Equation Model of relationships between cultural practice, Aboriginal language literacy, empowerment, and wellbeing for all participants. Goodness of fit: $\chi^{2}=49.4, d f=15 ; \chi^{2} / d f=$ $3.29, p<0.001$; RMSEA = $0.052(0.037,0.069)$; $\mathrm{SRMR}=0.036$; $\mathrm{CFI}=0.99$; $\mathrm{TLI}=0.98 ; \mathrm{PNFI}=0.53$. ${ }^{* *} p<0.01^{* * *} p<0.001$ 
There were direct associations between cultural practice and Aboriginal language literacy $(\beta=0.32$ $[0.24,0.40], p=0.005)$, and between Aboriginal language literacy and wellbeing $(\beta=0.25[0.17,0.31]$, $p=0.020)$. Likewise, cultural practice was associated with empowerment $(\beta=0.16[0.01,0.27, p=$ $0.035)$, and empowerment with wellbeing $(\beta=0.14[0.05,0.22], p=0.007)$. Preliminary analysis identified a statistically significant negative relationship between cultural practice and wellbeing $(\beta=$ $-0.11[-0.18,-0.031], p=0.016)$, inconsistent with literature and community consultations in the development of the Interplay Research Project and suggesting more complex interplay, which was explored through mediation analysis (Cairney et al., 2017).

Cultural practice was indirectly associated with well-being through Aboriginal language literacy $(\beta=$ $0.081[0.049,0.12], p=0.012)$, and through empowerment $(\beta=0.033[0.015,0.061], p=0.003)$, and the total relationship between cultural practice and wellbeing was not statistically significant $(\beta=-0.006$ $-0.071,0.058], p=0.93$ ). Thus, the model shows competitive mediation (Zhao, Lynch, \& Chen, 2010) whereby positive indirect relationships through both Aboriginal language literacy and empowerment mediate the negative direct relationship between cultural practice and wellbeing.

The effects of age were considered through multi-group analysis. When the pathway between cultural practice and wellbeing was constrained to be equal for each age group, there was no difference between the models for younger and older research participants $\left(\chi^{2}=0.90, d f=1, p=0.34\right)$.

In the multi-group analysis by gender, the relationship between cultural practice and wellbeing was constrained to be equal for males and females. This demonstrated differences between the relationships for males and females $\left(\chi^{2}=10.8, d f=1, p=0.001\right)$, so separate models were constructed for female and male participants, as shown in Figures 4 and 5.

Male and female participants showed different statistical relationships between cultural practice and wellbeing, as shown in Table 5. For males, there was a positive indirect relationship between cultural practice and wellbeing $(\beta=0.17[0.10,0.27], p=0.003)$ with both direct and total relationships nonsignificant; while for females, the direct negative relationship between cultural practice and wellbeing ( $\beta$ $=-0.25[-0.37,-0.11], p=0.02)$ was in competitive mediation with indirect positive relationship ( $\beta=$ $0.11[0.072,0.15], p=0.007)$. The total relationships between cultural practice and wellbeing were nonsignificant for both males and females $(\beta=0.008[-0.049,0.43], p=0.24 ; \beta=-0.078[-0.18,0.43], p=$ $0.23)$.

Finally, Aboriginal language literacy and empowerment were associated with wellbeing for females $(\beta=$ $0.39[0.30,0.49], p=0.004 ; \beta=0.17[0.067,0.29], p=0.005)$, but not males $(\beta=0.079[-0.030,0.16]$, $p=0.17 ; \beta=0.11[-0.015,0.23], p=0.09)$, as shown in Table 6 , leading to the weaker but statistically significant relationships for all participants. 


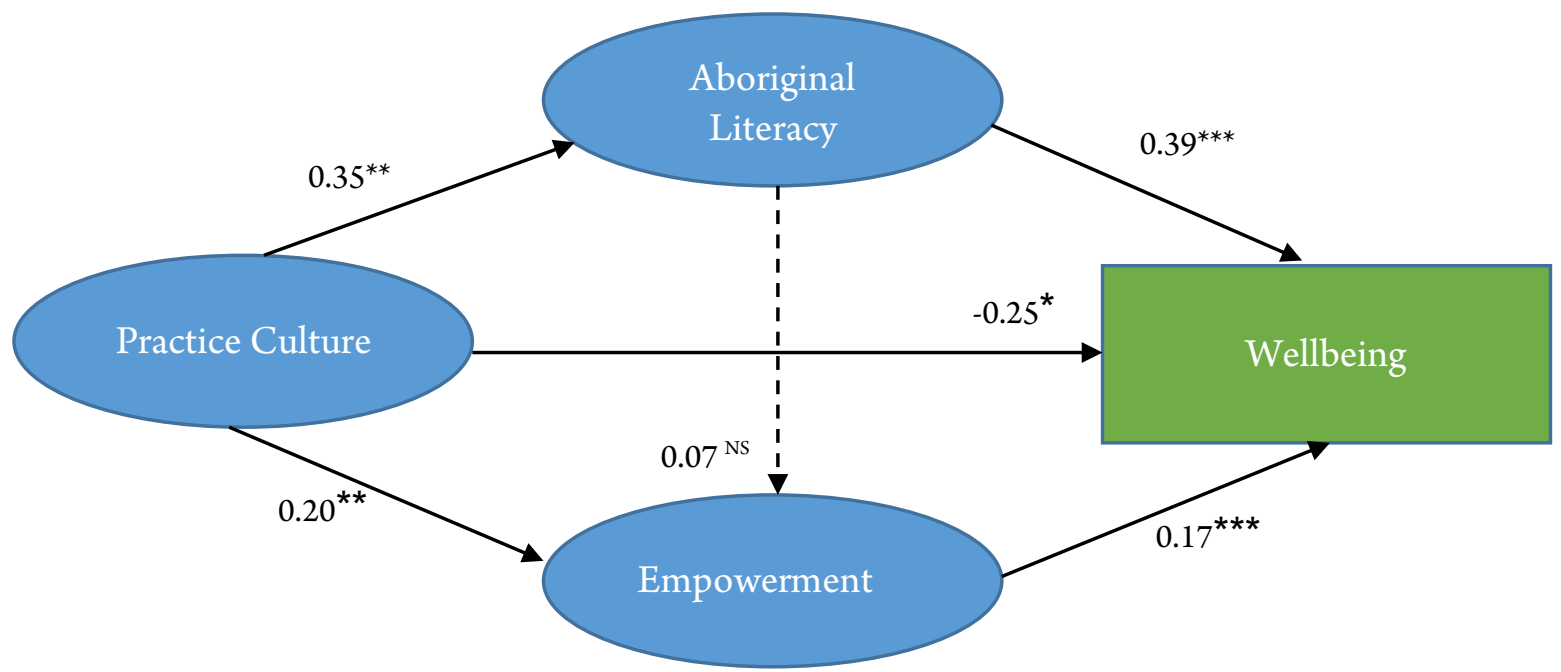

Figure 4. Structural equation model of relationships between cultural practice, Aboriginal language literacy, empowerment, and wellbeing for female participants. Goodness of fit: $\chi^{2}=65.8, d f=15$; $\chi^{2} / d f=4.38, p<0.001 ; \mathrm{RMSEA}=0.083(0.063,0.104)$; $\mathrm{SRMR}=0.067$; CFI = 0.97; TLI = 0.97; $\mathrm{PNFI}=0.52$.

${ }^{*} p<0.05^{* *} p<0.01^{* * *} p<0.001^{\mathrm{NS}}=$ not significant

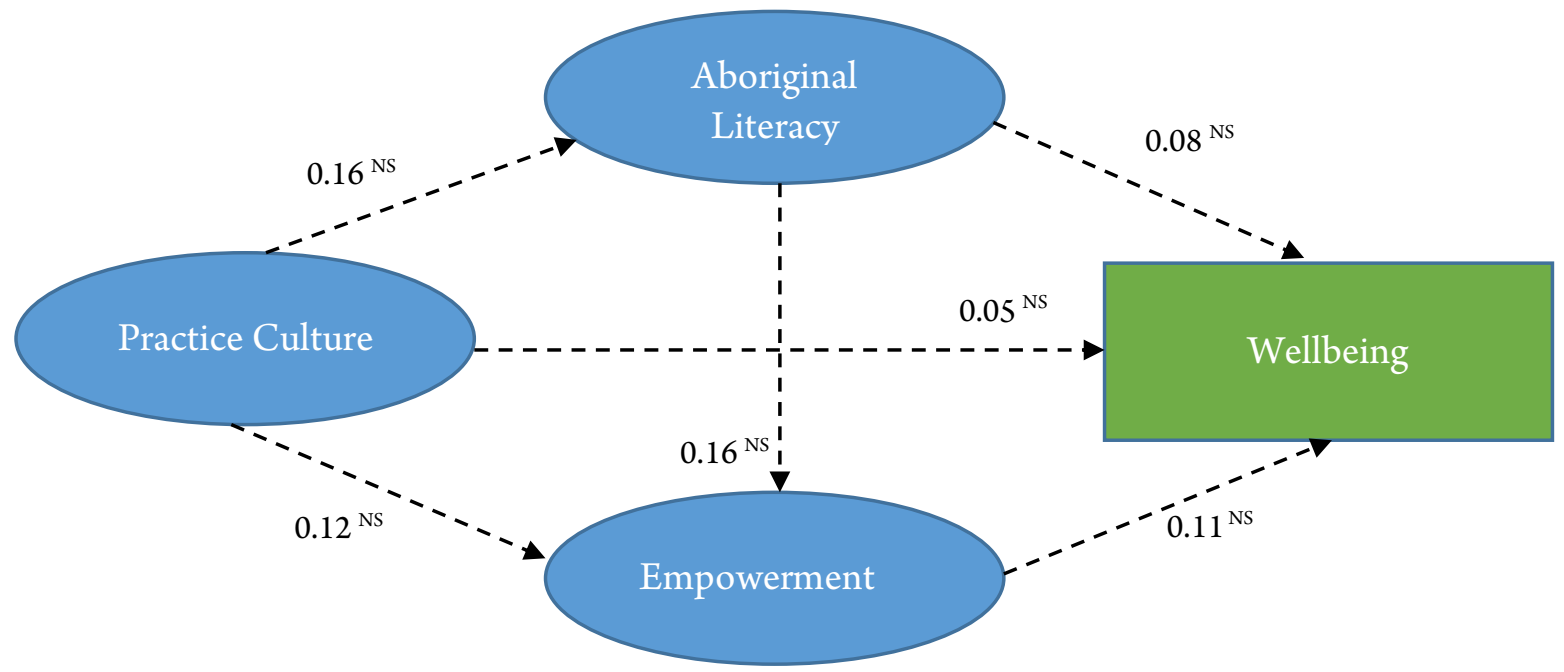

Figure 5. Structural equation model of relationships between cultural practice, Aboriginal language literacy, empowerment, and wellbeing for male participants. Goodness of fit: $\chi^{2}=19.5, d f=15$; $\chi^{2} / d=1.30, p=0.19 ; \mathrm{RMSEA}=0.029(0.00,0.062)$; $\mathrm{SRMR}=0.040 ; \mathrm{CFI}=0.98$; TLI $=0.99 ; \mathrm{PNFI}=$ 0.53

${ }^{\mathrm{NS}}=$ not significant 
Table 5. Relationships Between Cultural Practice and Wellbeing for Males, Females, and All Participants

\section{Wellbeing}

\begin{tabular}{lccc} 
Cultural Practice & Males $(\boldsymbol{n}=352)$ & Females $(\boldsymbol{n}=489)$ & All participants $(\boldsymbol{n}=\mathbf{8 4 1})$ \\
\cline { 2 - 4 } Direct relationship & 0.048 & -0.25 & -0.11 \\
& {$[-0.085,0.18]$} & {$[-0.37,-0.11]$} & {$[-0.18,-0.031]$} \\
& $p=0.58$ & $p=0.02^{*}$ & $p=0.016^{*}$ \\
Indirect & 0.174 & & 0.040 \\
relationship & {$[0.105,0.273]$} & {$[0.072,0.15]$} & {$[0.007,0.105]$} \\
& $p=0.003^{* *}$ & $p=0.007^{* *}$ & $p=0.004^{* *}$ \\
Total relationship & 0.008 & -0.078 & -0.006 \\
& {$[-0.049,0.21]$} & {$[-0.18,0.43]$} & {$[-0.058,0.071]$} \\
& $p=0.24$ & $p=0.23$ & $p=0.93$
\end{tabular}

Note. Relationships shown as $\beta[95 \% \mathrm{CI}], p$ value.

${ }^{*} p<0.05 ;{ }^{* *} p<0.01 ;{ }^{* * *} p<0.001$

Table 6. Relationships Between Aboriginal Language Literacy and Empowerment, and Wellbeing for Males, Females, and All Participants

\section{Wellbeing}

\begin{tabular}{lccc}
\cline { 2 - 4 } & Males $(\boldsymbol{n}=\mathbf{3 5 2})$ & Females $(\boldsymbol{n}=489)$ & All participants $(\boldsymbol{n}=\mathbf{8 4 1})$ \\
\hline Aboriginal language & 0.079 & 0.39 & 0.25 \\
literacy & {$[-0.030,0.16]$} & {$[0.30,0.49]$} & {$[0.17,0.31]$} \\
& $p=0.17$ & $p=0.004^{* *}$ & $p=0.020^{*}$ \\
Empowerment & 0.11 & & 0.14 \\
& {$[-0.015,0.23]$} & {$[0.067,0.29]$} & {$[0.050,0.22]$} \\
& $p=0.09$ & $p=0.005^{* *}$ & $p=0.007^{* *}$ \\
\hline
\end{tabular}

Note. Relationships shown as $\beta[95 \% \mathrm{CI}] ; p$ value

${ }^{*} p<0.05 ;{ }^{* *} p<0.01$; ${ }^{* * *} p<0.001$ 


\section{Discussion}

In the Interplay model of wellbeing for young adult Aboriginal Australians in remote regions, practising culture was associated with both Aboriginal language literacy and empowerment, each of which were associated with wellbeing in the model with all participants. However, the effects were significant among women, but not men, in models by gender.

\section{Cultural Practice}

The Interplay structural equation model showed no overall relationship between cultural practice and wellbeing for Aboriginal Peoples in remote Australia. Among women, the model identified positive direct relationships between cultural practice and both Aboriginal language literacy and empowerment, which in turn had a positive relationship with wellbeing and counterbalanced the negative direct relationship between cultural practice and wellbeing. These relationships highlight the importance of Aboriginal language literacy and empowerment, and the complexity of interplaying priorities for wellbeing, including differences between men and women.

In the model, relationships between cultural practice and wellbeing, including mediation by Aboriginal language literacy and empowerment, were different for male and female participants. Gender differences in cultural practices for Aboriginal Australians are well known and recognised in some service provision: For example, through the practice of separating Aboriginal men and women in work teams, planning consultations, networking, and conferences (Davies, Walker, \& Maru, 2017). Thus, the Interplay research involving young Aboriginal Peoples in remote regions shows that gender should be included as an explanatory variable in future research into wellbeing and related constructs.

\section{Aboriginal Language Literacy}

Wellbeing increased by 0.25 for each standard deviation increase in Aboriginal language literacy — the strongest relationship to wellbeing identified within the Interplay framework, driven by the effects among women (Cairney et al., 2017). For women, Aboriginal language literacy also mediated the relationship between cultural practice and wellbeing.

Relationships between wellbeing and Aboriginal language literacy, especially for women, highlight the importance of Aboriginal languages, which affirm cultural identity, self-efficacy, and resilience of Aboriginal Australians (Fogarty, 2012). The NATSISS showed that literacy in Aboriginal languages is associated with higher levels of formal education and paid employment, and with participation in cultural activities. These relationships suggest that people who are literate in both Aboriginal languages and English, which is more often used in employment, are well integrated in both mainstream and Aboriginal societies (Biddle \& Swee, 2012). Re-establishing government support for bilingual Aboriginal education will contribute to strengthening languages, thus enhancing rights of Aboriginal Peoples to their language (Nicholls, 2005; Schultz, Abbott, Yamaguchi, \& Cairney, 2018).

The relationship between Aboriginal literacy and wellbeing identified in the Interplay project reflects a global phenomenon in which Indigenous language literacy promotes identity, empowerment, and wellbeing (United Nations, 2014). Efforts to enhance Aboriginal language literacy may provide multiple benefits for individuals, communities, and Australia's international reputation. Further research is 
required to explore how Aboriginal language literacy impacts Aboriginal men, particularly because men have higher overall levels of Aboriginal language knowledge than women (Biddle \& Swee, 2012).

\section{Empowerment}

For women, increased empowerment had a direct positive relationship with wellbeing and a mediating effect on the relationship between cultural practice and wellbeing. The direct link between empowerment and wellbeing for women in the Interplay model suggests that the function of health care, education services, Aboriginal organisations, and businesses in contributing to empowerment should be considered (McCalman, 2013; McEwan, Tsey, McCalman, \& Travers, 2010).

Relationships between gender and empowerment for Aboriginal Australians reflect how Aboriginal men and women hold different spheres of influence and authority, and this is demonstrated through on-going separation of aspects of men's and women's lives (Fredericks et al., 2017). The findings in the Interplay project that relationships with empowerment differed for men and women are important and novel: Other studies of empowerment for Aboriginal Peoples have not published analyses by gender (McCalman, Bainbridge, Brown, Tsey, \& Clarke, 2018). Research on empowerment for Aboriginal Australians has often arisen from non-Aboriginal concepts of power related to male physical and economic power. These differ from Aboriginal understandings of power, where power is related to cultural knowledge authority (Fredericks et al., 2017). Further research is needed to explore constructs of empowerment for Aboriginal Peoples in relation to gender.

Programs that have shown success in addressing empowerment among Australian Aboriginal Peoples are available through health, wellbeing, education, and employment service settings; however, political, ideological, and economic conditions have limited program implementation (McCalman et al., 2018). Currently, Australian health care services are funded to address clinical indicators for Aboriginal Peoples, rather than to contribute to empowerment, despite demonstrated benefits of empowerment interventions (Tsey et al., 2005). Addressing empowerment through health services, especially for women, may be a key element in the transformative change in health care needed to improve both health and wellbeing for Aboriginal Australians (Houston, 2016). For Aboriginal men, there is a need to address barriers to health service access (Canuto, Wittert, Harfield, \& Brown, 2018).

Effective empowerment programs based on Aboriginal leadership and relatedness in schools, other educational institutions, and Aboriginal organisations can enhance wellbeing. However, Aboriginal Peoples require greater influence within policy and program circles in order to overcome barriers to the implementation of additional programs that empower Aboriginal Peoples (McCalman, 2013).

\section{Australian Policy Implications}

Australian governments have long sought to reduce measures of socio-economic disadvantage for Aboriginal Peoples (Altman, 2009). The current initiative is entitled Closing the Gap and has widespread support for its focus on reducing educational, employment, and health disadvantages of Aboriginal and Torres Strait Islander Peoples, particularly in remote regions (Commonwealth of Australia: Department of Prime Minister and Cabinet, 2017). However, government-defined nationwide targets do not adequately reflect the diversity of Aboriginal Peoples, and Aboriginal Peoples' aspirations are not reflected in government strategies to meet targets. An alternative policy approach 
would recognise the agency of Aboriginal Peoples and facilitate the development of targets and strategies that address their own needs (Altman, 2009). Aboriginal language literacy and empowerment as indicators of education could be considered as additional targets in the Close the Gap initiative, reflecting Aboriginal aspirations and human development in line with findings of the Interplay research.

Australia's Closing the Gap initiative makes repeated references to the importance of Aboriginal culture (Commonwealth of Australia: Department of Prime Minister and Cabinet, 2018), and culture was a priority of the Interplay wellbeing project. However, the complexity of relationships between cultural practice and wellbeing suggests that greater awareness is needed of how policies and services address culture and cultural practice. Policy and services focused on empowerment and Aboriginal literacy in alignment with cultural practice may be more effective in promoting wellbeing.

For Aboriginal Peoples from remote regions, education, employment, and health are not simply goals, but also the means through which to enhance their wellbeing (Cairney et al., 2017). Assumptions from government and other non-Aboriginal sectors of society that education should lead to employment and thereby contribute to the growth of the wider economy are not relevant to many Aboriginal Peoples in remote Australia. Rather, education should support Aboriginal languages and culture, affirm connection to country, and strengthen identities in order to promote wellbeing. The notion of direct transition from education to employment was not supported in the Interplay project, consistent with other work with Aboriginal Peoples in remote Australia (McRae-Williams, Guenther, Jacobsen, \& Lovell, 2016; Schultz et al., 2018).

Bureaucratising Aboriginal culture can have negative impacts when culture is built into service plans developed externally, rather than through genuine ongoing engagement and empowerment of the communities involved (Fache, 2014). When the underlying bureaucracy is insensitive to key Aboriginal relationships and knowledge, using Aboriginal Peoples' culture as a tool to promote government policy can disempower people and negatively impact their wellbeing (Nadasdy, 2005). Implementation of cultural practices in unequal settings can reinforce dominant cultural mores that overrule Aboriginal values, methods, and institutions (Ens, Finlayson, Preuss, Jackson, \& Holcombe, 2012). When nonAboriginal Peoples do not recognise their own cultural practices and norms, yet remain the dominant service providers, their efforts to promote cultural practice may not contribute to Aboriginal wellbeing. Refreshment of the Closing the Gap initiative has highlighted the importance of empowerment and strong connections to country, rather than narrow representations of Aboriginal culture (Parter, Wilson, \& Hartz, 2019).

The fundamental implication for Australian policy is that culture is a key component of wellbeing for Aboriginal Peoples of remote regions, but implementation of programs based on cultural practices must also entail other components. The Interplay project demonstrates that for women empowerment and Aboriginal language literacy mediate the link from cultural practice to wellbeing, while further research with Aboriginal men is required to quantify the insights that emerged in the development of the wellbeing research framework.

\section{International Implications}

Structural equation modelling enabled quantification and comparison of relationships between constructs such as wellbeing and empowerment that are meaningful across different cultures. This 
process translates people's stories into numbers to provide the empirical accountability often required by governments.

The Interplay structural equation models developed for Aboriginal Peoples in remote Australia showed the importance of Aboriginal language literacy for wellbeing. The importance of languages for the health and wellbeing of Indigenous Peoples globally is increasingly being recognised (Flood \& Rohloff, 2018). Loss of Indigenous languages is contributing to loss of Indigenous knowledge communicated through these languages (Nettle \& Romaine, 2000). International bodies have recommended that all governments recognise, strengthen, and re-vitalise Indigenous languages for the benefit of individuals, communities, and nations (United Nations, 2014), and this research highlights the association between Indigenous language literacy and wellbeing.

The Interplay model suggests that for Aboriginal women in remote Australia, empowerment may contribute both directly and indirectly to wellbeing, and this is consistent with international recognition that empowerment for Indigenous Peoples is a critical tool for building equity in human development (United Nations, 2015). However, empowerment strategies must be developed locally for people to be empowered because of the importance of participation in processes of empowerment, which cannot be standardised across populations (Wallerstein, 2006).

\section{Limitations}

The research was conducted in Australian Aboriginal communities in regions classified as remote, so generalisation is limited to this Aboriginal population (Australian Bureau of Statistics, 2014). For many Aboriginal Peoples, statistical classifications of remoteness are arbitrary. From their perspective, remoteness can also be seen as a reflection of presence on ancestral lands (Rose, 2004). Participation was limited to people aged 15 to 34, so results may not be relevant to other age groups, both because of how priorities change over the life course and because of the changing Aboriginal policy frameworks that shape people's lives (Altman, Biddle, \& Hunter, 2004).

Both the communities and individuals involved in the research were self-selected and, although efforts were made to include diverse communities, the distinctiveness of each Aboriginal community may limit generalisation. Data collection by Aboriginal community researchers in their home communities may have led to information bias. Further, gender-specific concerns and language and communication issues were potential limitations.

The research focussed on positive attributes to counter the pervasive negative representation of Aboriginal Peoples, and this may have contributed to bias in both collection and interpretation of results. Despite efforts to reach common understandings among researchers of each of the questions, translation and interpretation across languages and cultures may have been a limitation. Relationships are associations between variables and do not suggest causation.

\section{Conclusion}

Delivery of effective services can improve people's wellbeing. As an outcome measure, wellbeing reflects individual aspirations and priorities, overcoming the cultural bias of other outcome measures. The Interplay project identified and explored wellbeing priorities for Aboriginal Peoples in remote regions of 
Australia to guide service provision. For women, Aboriginal language literacy and empowerment showed both direct and indirect relationships with wellbeing, suggesting including Aboriginal language literacy and empowerment in education, employment, and health policy and services may have farreaching benefits. For men, neither Aboriginal language literacy, empowerment, nor cultural practice were statistically associated and wellbeing. Overall, relationships between cultural practice and wellbeing are a complex interplay of factors, but empowerment and Aboriginal language literacy appear to be important priorities. Further research to explore relationships between Aboriginal language literacy, empowerment, and wellbeing among Aboriginal men and women is required to understand the different needs of each gender.

\section{References}

Adler, A., \& Seligman, M. E. (2016). Using wellbeing for public policy: Theory, measurement, and recommendations. International Journal of Wellbeing, 6(1), 1-35.

doi: https://doi.org/10.5502/ijw.v6i1.429

Altman, J. (2007). Alleviating poverty in remote Indigenous Australia: The role of the hybrid economy. Retrieved from http://caepr.cass.anu.edu.au/research/publications/alleviating-povertyremote-indigenous-australia-role-hybrid-economy

Altman, J. (2009). Beyond Closing the Gap: Valuing diversity in Indigenous Australia (CAEPR Working Paper No. 54/2009). Retrieved from http://caepr.anu.edu.au/sites/default/files/Publications/WP/CAEPRWP54.pdf

Altman, J., Biddle, N., \& Hunter, B. (2004). Indigenous socioeconomic change 1971 - 2001: A historical perspective (Discussion Paper 266/2004). Retrieved from http://caepr.cass.anu.edu.au/research/publications/indigenous-socioeconomic-change-19712001-historical-perspective

Arbuckle, J. L. (2017). Amos (Version 25.0). Chicago, IL: IBM SPSS.

Australian Bureau of Statistics. (2011). 2011 Census quickstats. Retrieved from http://www.abs.gov.au/websitedbs/censushome.nsf/home/quickstats?opendocument\&navpo $\underline{s=220}$

Australian Bureau of Statistics. (2014). The Australian Statistical Geography Standard (ASGS) remoteness structure. Retrieved from http://www.abs.gov.au/websitedbs/d3310114.nsf/home/remoteness+structure

Australian Bureau of Statistics. (2015). 4159.0 - General Social Survey: Summary results, Australia, 2014. Retrieved from http://www.abs.gov.au/ausstats/abs@.nsf/mf/4159.0

Australian Bureau of Statistics. (2016). 4714.0 - National Aboriginal and Torres Strait Islander Social Survey, 2014-15. Retrieved from http://www.abs.gov.au/AUSSTATS/abs@.nsf/exnote/4714.0 
Australian Institute of Health and Welfare. (2014). Remoteness and the health of Indigenous Australians. In Australian Institute of Health and Welfare (Ed.), Australia's Health Series no. 14: Australia's health 2014(Cat. no. AUS 178). Retrieved from https://www.aihw.gov.au/getmedia/3fae0eb7-b2be-4ffc-9903-a414388af557/7 7-indigenoushealth-remoteness.pdf.aspx

Australian Institute of Health and Welfare. (2015). The health and welfare of Australia's Aboriginal and Torres Strait Islander Peoples 2015 (Cat. no. IHW 147). Retrieved from https://www.aihw.gov.au/reports/indigenous-health-welfare/indigenous-health-welfare2015/contents/table-of-contents

Australian Museum. (2017). Glossary of Indigenous Australia terms. Retrieved from https://australianmuseum.net.au/learn/cultures/atsi-collection/cultural-objects/glossaryindigenous-australia-terms/

Barber, M. (2015). Rangers in place: The wider Indigenous community benefits of Yirralka Rangers in Blue Mud Bay, northeast Arnhem Land : Final report. Retrieved from https://www.nespnorthern.edu.au/wp-content/uploads/2015/10/2.1.19 rangers in place final report.pdf

Biddle, N. (2012). Indigenous language usage. Indigenous Population Project 2011 Census papers. Retrieved from http://caepr.cass.anu.edu.au/research/publications/indigenous-language-usage

Biddle, N., \& Swee, H. (2012). The relationship between wellbeing and Indigenous land, language, and culture in Australia. Australian Geographer, 43(3), 215-232. doi: https://doi.org/10.1080/00049182.2012.706201

Burgess, C. P., Johnston, F. H., Berry, H. L., McDonnell, J., Yibarbuk, D., Gunabarra, C., ... Bailie, R. S. (2009). Healthy country, healthy people: The relationship between Indigenous health status and "caring for country." Medical Journal of Australia, 109, 567-572.

Cairney, S., \& Abbott, T. (2014). Aboriginal wellbeing in a 'red dirt economy.' Journal of Australian Indigenous Issues, 17(4), 5-22.

Cairney, S., Abbott, T., Quinn, S., Yamaguchi, J., Wilson, B., \& Wakerman, J. (2017). Interplay Wellbeing Framework: A collaborative methodology 'bringing together stories and numbers' to quantify Aboriginal cultural values in remote Australia. International Journal for Equity in Health, 16 (68) doi: https://doi.org/10.1186/s12939-017-0563-5

Cairney, S., Abbott, T., \& Yamaguchi, J. (2015). Study protocol: The Interplay Wellbeing Framework and methodology to assess wellbeing in Aboriginal and Torres Strait Islander People in remote Australia (CRC-REP Working Paper CW024). Retrieved from http://www.crcrep.com.au/resource/CW024_StudyProtocol_InterplayWellbeingFrameworkMethodology.pd $\underline{f}$ 
Canuto, K., Wittert, G., Harfield, S., \& Brown, A. (2018). "I feel more comfortable speaking to a male": Aboriginal and Torres Strait Islander men's discourse on utilizing primary health care services. International Journal for Equity in Health, 17, 185. doi: https://doi.org/10.1186/s12939-018$\underline{0902-1}$

Commonwealth of Australia: Department of Prime Minister and Cabinet. (2017). Closing the Gap: Prime Minister's report 2017. Retrieved from https://www.pmc.gov.au/resourcecentre/indigenous-affairs/closing-gap-prime-ministers-report-2017

Commonwealth of Australia: Department of Prime Minister and Cabinet. (2018). Closing the Gap: Prime Minister's report 2018. Retrieved from https://www.pmc.gov.au/indigenousaffairs/closing-gap

Cooperative Research Centre for Remote Economic Participation. (2017). Cooperative Research Centre for Remote Economic Participation (CRC-REP) Exit report. Retrieved from https://old.crc-rep.com/sites/default/files/CRC-REP ExitReport.pdf

Davies, J., Campbell, D., Campbell, M., Douglas, J., Hueneke, H., LaFlamme, M., ...Walsh, F. (2010). Livelihoods inLand ${ }^{T M}$ : Promoting health and wellbeing outcomes from desert Aboriginal land management. Retrieved from http://nintione.com.au/resource/dkcrc-report-78-livelihoods-inland health-and-wellbeing-from-desert-alm.pdf

Davies, J., Walker, J., \& Maru, Y. T. (2017). Warlpiri experiences highlight challenges and opportunities for gender equity in Indigenous conservation management in arid Australia. Journal of Arid Environments, 149, 40-52. doi: https://doi.org/10.1016/j.jaridenv.2017.10.002

Dockery, A. M. (2012). Do traditional culture and the wellbeing of Indigenous Australians? Evidence from the 2008 NATSISS. doi: http://doi.org/10.22459/caepr32.11.2012.13tps

Ens, E. J., Finlayson, M., Preuss, K., Jackson, S., \& Holcombe, S. (2012). Australian approaches for managing 'country' using Indigenous and non-Indigenous knowledge. Ecological Management \& Restoration, 13 (1), 100-107. doi: https://doi.org/10.1111/j.1442-8903.2011.00634.x

Fache, E. (2014). Caring for country, a form of bureaucratic participation. Conservation, development, and neoliberalism in Indigenous Australia. Anthropological Forum, 24(3), 267-286. doi: https://doi.org/10.1080/00664677.2014.939576

Flood, D., \& Rohloff, P. (2018). Indigenous languages and global health. Lancet Global Health, 6, e134e135. doi: https://doi.org/10.1016/S2214-109X(17)30493-X

Fogarty, B. (2012). Country as classroom. In J. Altman \& S. Kerins (Eds.), People on country: Vital landscapes, Indigenous futures (pp. 82-93). Sydney, Australia: Federation Press.

Fredericks, B., Daniels, C., Judd, J., Bainbridge, R., Clapham, K., Longbottom, M., ... Ball, R. (2017). Gendered Indigenous health and wellbeing within the Australian health system: A review of the literature. Retrieved from https://api.research- 
repository.uwa.edu.au/portalfiles/portal/24961696/Gendered_Indigenous_Health and Well being within the Australian_Health System. A Review of the Literature.pdf.pdf

Haswell, M. R., Kavanagh, D., Tsey, K., Reilly, L., Cadet-James, Y., Laliberté, A., . . . Doran, C. (2010). Psychometric validation of the growth and empowerment measure (GEM) applied with Indigenous Australians. Australian and New Zealand Journal of Psychiatry, 44, 791-799. doi: https://doi.org/10.3109/00048674.2010.482919

Hill, R., Pert, P. L., Davies, J., Robinson, C. J., Walsh, F., \& Falco-Mammone, F. (2013). Indigenous land management in Australia: Extent, scope, diversity, barriers and success factors. Retrieved from http://www.agriculture.gov.au/SiteCollectionDocuments/naturalresources/landcare/submissions/ilm-report.pdf

Hooper, D., Coughlan, J., \& Mullen, M. (2008). Structural equation modelling: Guidelines for determining model fit. Electronic Journal of Business Research Methods, 6(1), 53-60.

Houston, S. (2016). We need transformative change in Aboriginal health. Medical Journal of Australia, 205 (1), 17-18. doi: https://doi.org/10.5694/mja16.00496

Hunt, J. (2012). North to South? In J. Altman \& S. Kerins (Eds.), People on country: Vital landscapes Indigenous futures (pp. 94-118). Leichhardt, NSW: Federation Press.

Kline, R. B. (2016). Principles and practice of structural equation modeling fourth edition (4th ed.). New York, NY: Guilford Press.

Markham, F., \& Biddle, N. (2018). Income, poverty and inequality. Retrieved from http://caepr.cass.anu.edu.au/sites/default/files/docs/CAEPR_Census_Paper_2.pdf

Marmion, D., Obata, K., \& Troy, J. (2014). Community, identity, wellbeing: The report of the Second National Indigenous Languages Survey. Retrieved from http://aiatsis.gov.au/publications/products/community-identity-wellbeing-report-secondnational-indigenous-languages-survey

McCalman, J., Bainbridge, R., Brown, C., Tsey, K., \& Clarke, A. (2018). The Aboriginal Australian Family Wellbeing Program: A historical analysis of the conditions that enabled its spread. Frontiers in Public Health, 6, 26. doi: https://doi.org/10.3389/fpubh.2018.00026

McCalman, J. R. (2013). The transfer and implementation of an Aboriginal Australian wellbeing program: A grounded theory study. Implementation Science, $8,129$. doi: $\underline{\text { https://doi.org/10.1186/1748-5908-8-129 }}$

McEwan, A. B., Tsey, K., McCalman, J., \& Travers, H. J. (2010). Empowerment and change management in Aboriginal organisations: A case study. Australian Health Review, 34, 360-367. doi: https://doi.org/10.1071/ah08696

McRae-Williams, E., Guenther, J., Jacobsen, D., \& Lovell, J. (2016). What are the enablers of economic participation in remote and very remote Australia, and how can we identify them? Learning 
Communities: International Journal of Learning in Social Contexts [Special Issue: Synthesis \& Integration], 19, 6-25. doi: https://doi.org/10.18793/LCJ2016.19.02

Nadasdy, P. (2005). The anti-politics of TEK: The institutionalization of co-management discourse and practice. Anthropologica, 47(2), 215-232.

Nettle, D., \& Romaine, S. (2000). Vanishing voices: The extinction of the world's languages (pp. 94137). New York: Oxford University Press.

Nguyen, O. K., \& Cairney, S. (2013). Literature review of the interplay between education, employment, health and wellbeing for Aboriginal and Torres Strait Islander People in remote areas: Working towards an Aboriginal and Torres Strait Islander wellbeing framework (CRCREP Working Paper CW013). Retrieved from http://www.crcrep.com.au/resource/CW013 InterplayLiteratureReview_TowardsWellbeingFramework.pdf

Nicholls, C. (2005). Death by a thousand cuts: Indigenous language bilingual education programmes in the Northern Territory of Australia, 1972-1998. International Journal of Bilingual Education and Bilingualism, 8 (2-3), 160-177. doi: https://doi.org/10.1080/13670050508668604

Nitzl, C., Roldan, J. L., \& Cepeda, G. (2016). Mediation analysis in partial least squares path modeling: Helping researchers discuss more sophisticated models. Industrial Management \& Data Systems, 116(9), 1849-1864. doi: https://doi.org/10.1108/IMDS-07-2015-0302

OECD. (2017). How's life? 2017: Measuring wellbeing. doi: https://doi.org/10.1787/how life-2017en

Parter, C., Wilson, S., \& Hartz, D. L. (2019). The Closing the Gap (CTG) refresh: Should Aboriginal and Torres Strait Islander culture be incorporated in the CTG framework? How? Australian New Zealand Journal of Public Health, 43 (1), 5-7. doi: https://doi.org/10.1111/1753$\underline{6405.12850}$

Pease, B. (2002). Rethinking empowerment: A postmodern reappraisal for emancipatory practice. British Journal of Social Work, 32, 135-147. doi: https://doi.org/10.1093/bjsw/32.2.135

Rose, D. B. (2004). Reports from a wild country: Ethics for decolonisation. Sydney, Australia: UNSW Press.

Schultz, R., Abbott, T., Yamaguchi, J., \& Cairney, S. (2018). Re-imagining Indigenous education for health, wellbeing and sustainable development in remote Australia. Creative Education, 9, 29502972. doi: https://doi.org/10.4236/ce.2018.916222

Smith, L. T. (2012). Decolonizing methodologies: Research and Indigenous people (2 ${ }^{\text {nd }}$ ed.). London, England: Zed Books.

Social Ventures Australia. (2016). Consolidated report on Indigenous Protected Areas following social return on investment analyses. Retrieved from 
https://www.pmc.gov.au/sites/default/files/publications/SROI-Consolidated-Report$\underline{\text { IPA } 1 . p d f}$

SPSS Inc. (2015). IBM SPSS Statistics Version 23. Armonk, NY: International Business Machines Corp.

Tov, W., \& Au, E. W. (2013). Comparing well-being across nations: Conceptual and empirical issues. In S. A. David, I. Boniwell, \& A. C. Ayers (Eds.), Oxford handbook of happiness (pp. 448-464). doi: https://doi.org/10.1093/oxfordhb/9780199557257.013.0035

Tsey, K., Travers, H., Gibson, T., Whiteside, M., Cadet-James, Y., Haswell-Elkins, M., ...Wilson, A. (2005). The role of empowerment through life skills development in building comprehensive primary health care systems in Indigenous Australia. Australian Journal of Primary Health, 11 (2), 16-26. doi: https://doi.org/10.1071/py05017

United Nations. (2014). Recommendations related to languages adopted by the Permanent Forum on Indigenous Issues. Retrieved from http://www.un.org/esa/socdev/unpfii/documents/2016/egm/language_recs_UNPFII_websi te.pdf

United Nations. (2015). Transforming our world: The 2030 Agenda for Sustainable Development(A/ RES/70//1). Retrieved from https://sustainabledevelopment.un.org/content/documents/21252030\%20Agenda\%20for\%2 0Sustainable\%20Development\%20web.pdf

Walker, B. W., Porter, D. J., \& Marsh, I. (2012). Fixing the hole in Australia's heartland: How government needs to work in remote Australia. Retrieved from https://eprints.utas.edu.au/15065/1/Fixing the hole in Australia\%27s_Heartland.pdf

Wallerstein, N. (2006). What is the evidence on effectiveness of empowerment to improve health? Health Evidence Network report. Retrieved from http://www.euro.who.int/__data/assets/pdf file/0010/74656/E88086.pdf

Whiteside, M., Tsey, K., \& Earles, W. (2010). Locating empowerment in the context of Indigenous Australia. Australian Social Work, 64(1), 113-129. doi: https://doi.org/10.1080/0312407X.2010.533279

Williams, B., Brown, T., \& Onsman, A. (2010). Exploratory factor analysis: A five-step guide for novices. Journal of Emergency Primary Health Care, 8(3), Article 990399. doi: https://doi.org/10.33151/ajp.8.3.93

Wolf, E. J., Harrington, K. M., Clark, S. L., \& Miller, M. W. (2013). Sample size requirements for structural equation models: An evaluation of power, bias, and solution propriety. Educational Psychology Measurement, 76(6), 913-934. doi: https://doi.org/10.1177/0013164413495237 
Zhao, X., Lynch, J. G., \& Chen, Q. (2010). Reconsidering Baron and Kenny: Myths and truths about mediation analysis. Journal of Consumer Research, 37(2), 197-206.

doi: https://doi.org/10.1086/651257 